\title{
Heat Treatment of Cold Formed Springs Made from Oil Hardened and Tempered Spring Steel Wire
}

\author{
Veronika Geinitz ${ }^{1, a *}$, Ulf Kletzin ${ }^{1, b}$ \\ ${ }^{1}$ Technical University IImenau, Department of Mechanical Engineering, Institute for Design \\ and Precision Engineering, Machine Elements Group, PO Box 100565, 98684 Ilmenau, Germany \\ aVeronika.geinitz@tu-ilmenau.de, bulf.kletzin@tu-ilmenau.de
}

Keywords: spring steel, wire, cold forming, heat treatment, oil hardening, tempering, residual stresses, coil spring, mechanical properties

\begin{abstract}
The heat treatment after cold forming is used to decrease the residual stresses of springs, but the mechanical characteristics of the spring steel wires alters, too. This presentation describes the influence of the heat treatment technology (oven equipment, temperature, duration,...) to the properties and quality of helical compression springs made from oil hardened and tempered spring steel wire.
\end{abstract}

\section{Introduction}

Spring steel wires are made from very special manufactured high-tech steels with extremely high tensile strengths $R_{\mathrm{m}}$. These spring steel wires are characterized by an extremely high yield point, because they have to withstand high loads without plastic deformation. This specific spring wire property is useful for the spring function, but it leads also to significant residual stresses after spring cold forming due to high leveled spring-back.

These residual stresses have to be decreased significantly because residual stresses clearly reduce the load limit, the relaxation behavior and the durability of cold formed springs. That's why springs have to be heat treated after cold forming.

A large number of material properties, spring parameters, furnace characteristics and technology parameters should be considered when selecting the heat treatment temperature and time. Therefore the seemingly simple heat treatment becomes a complex process. The research group "Wire and springs" of Ilmenau Technical University conducted with a research project titled "Heat Treatment of Cold Formed Springs" [1]. The most important aims of the project were:

- analysis and characterization of different furnaces,

- measurement of heating curves and cooling curves of different wire pieces and of springs,

- calculation of typical time constants and heat transfer coefficients from heating and cooling curves,

- determination of convenient heat treatment temperatures as a function of wire material and spring function,

- determination of reduction of residual stresses,

- determination of variation of spring wire mechanical properties caused by heat treatment.

Very high-stressed springs are made from oil hardened and tempered wires, e.g. VDSiCr. This article describes the possible effect of heat treatment to the properties of springs made from VDSiCr.

\section{Residual stresses after cold forming (spring coiling) and after heat treatment}

Cold forming leads to bending residual stresses in the wire of the spring. The residual stresses on the inner spring side were determined by X-ray diffractometer, paticularly after cold forming without heat treatment and after different heat treatments of the springs. The different heat treatments varied in temperature and heat treatment duration (time). 
Typical heat treatment temperatures of springs made from oil hardened and tempered wires are in a range of $350^{\circ} \mathrm{C}$ to $420^{\circ} \mathrm{C}$. The bending residual stresses after cold forming determined at springs made from oil hardened and tempered wire with $d=6 \mathrm{~mm}$ and a spring index $w=5$, $\left(w=D_{\mathrm{m}} / d\right)$ were about $1100 \mathrm{MPa}$ (Fig. 1). A rest of the residual stresses remained in the wire after a heat treatment of $10 \mathrm{~min}$ up to $60 \mathrm{~min}$ even at high temperatures of $420^{\circ} \mathrm{C}$.

In Fig. 1 is to be seen, that

- the rest of the residual stresses after heat treatment depends on heat treatment temperature,

- very small heat treatment duration of about 10 min (the wire has just reached the set temperature) leads to a clearly reduction of residual stresses after a heat treatment with high temperatures

- the reduction of the residual stresses increases clearly with the heat treatment duration, especially with higher temperatures $\left(300^{\circ} \mathrm{C}, 350^{\circ} \mathrm{C}, 400^{\circ} \mathrm{C}\right)$. Therefore the effect of heat treatment with these temperatures depends on the heat treatment duration, too.

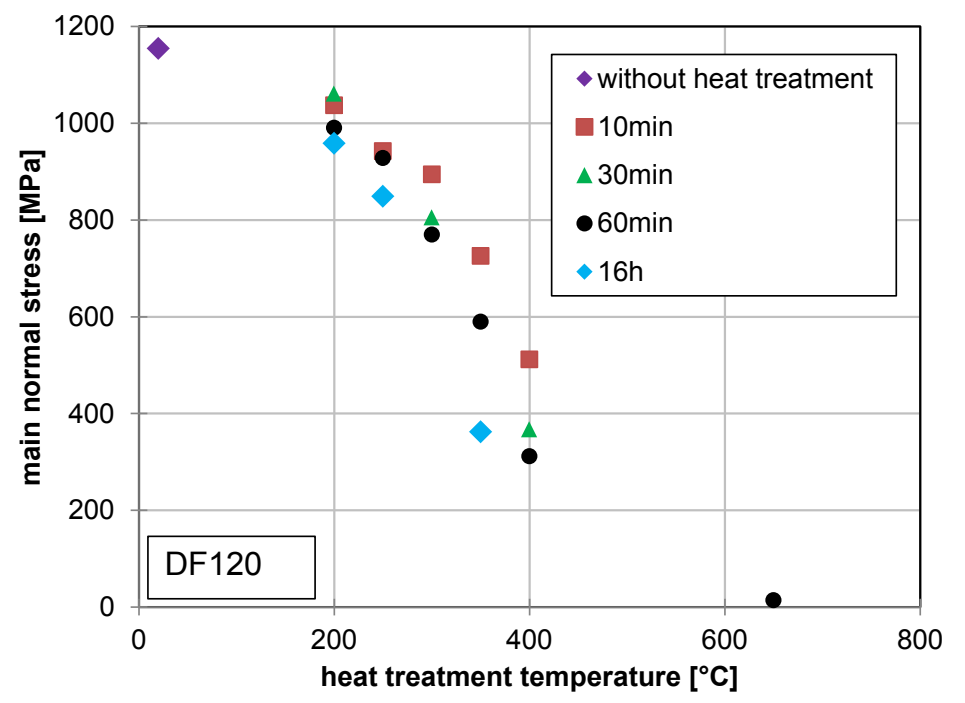

Fig. 1. Reduction of residual stresses on springs made from oil hardened and tempered wire, $d=6 \mathrm{~mm}, w=5$ and $n_{\mathrm{t}}=6.5$ after 22 different heat treatments

\section{Mechanical properties of oil hardened and tempered wire}

The mechanical parameters of spring steel wires vary due to heat treatment. Investigation of this fact was carried out by the research group "wire and springs" in several research projects $[3,4,5]$ with spring steel wires made from material described in [2].

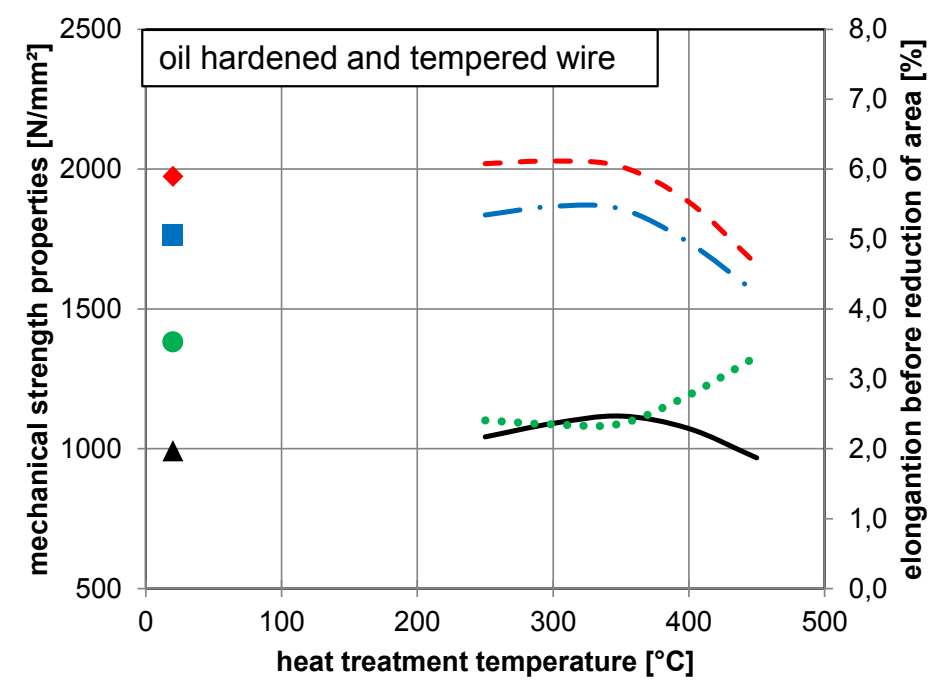

Fig. 2. Qualitative changes of the mechanical parameters as a function of the heat treatment temperature, Oil hardened and tempered wire: $\diamond---: R_{\mathrm{m}}$ (tensile strength) $\square-\cdot-: R_{\mathrm{p} 0.2}$ (yield stress $0.2 \%$ ) $\Delta-: \tau_{\mathrm{t} * 0.04}$ (torsion yield point) $\circ:: A_{\mathrm{g}}$ (elongation before reduction of area) 
Fig. 2 contains the qualitative variation of the tension test values and the torsion yield point of oil hardened and tempered wires as a function of the heat treatment temperature. At first tensile and torsion yield points $\left(R_{\mathrm{p} 0.2}, \tau_{\mathrm{t}^{*} 0.04}\right)$ as well as the tensile strength $R_{\mathrm{m}}$ increase up to temperatures $300^{\circ} \mathrm{C} \ldots 350^{\circ} \mathrm{C} . R_{\mathrm{m}}, R_{\mathrm{p} 0.2}$ and $\tau_{\mathrm{t}^{*} 0.04}$ decrease after heat treatment with temperatures more than $350^{\circ} \mathrm{C}$. Often this decrease is strongly pronounced on thin oil hardened and tempered spring steel wires. The strain before reduction of area $\mathrm{A}_{\mathrm{g}}$ (proportional elongation) decreases with increasing heat treatment temperatures at first and rises clearly with temperatures of more than $350^{\circ} \mathrm{C}$.

\section{Furnaces technology for heat treatment of cold formed springs}

There are (portable) continuous furnaces with small capacity and chamber furnaces (box-type furnaces) with large capacity which are used for heat treatment of cold formed springs. A chamber furnace is defined as an oven with batch supply, springs in boxes and a closed chamber.

The velocity of heated air close to the spring is the most important determining factor of the time, which is necessary to heat a spring to the set temperature [1]. Springs, heat treated in a chamber furnace, lie in boxes. Size and type of the boxes depend on the geometry of the chamber furnace (cylindrical, block-shaped) and the spring size. In most cases, the side walls and/or the bottom plate of the boxes are perforated.

Fig. 3 shows the air flow velocity on a perforated plate in an air duct as a result of a simulation. The perforated plate simulates the side walls or the bottom of a box. It is to be seen that the larger part of the air flows aside the barricade. In this case, the heat transfer from air to spring is significantly delayed.

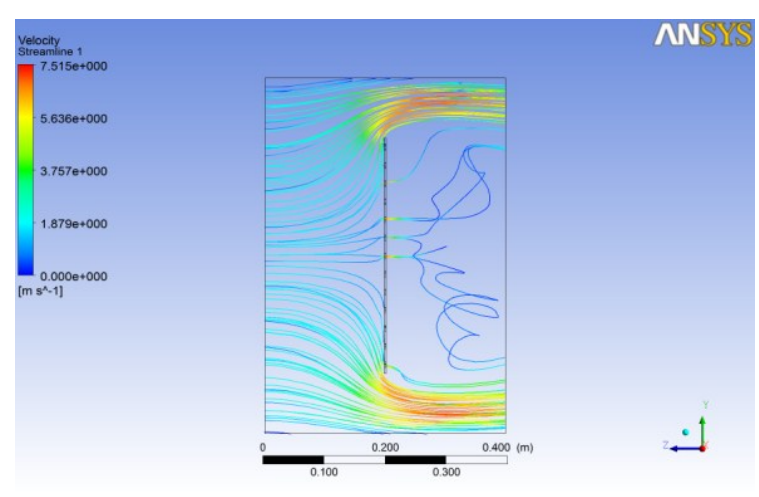

Fig. 3. Air flow velocity simulated: an air duct with a perforated plate

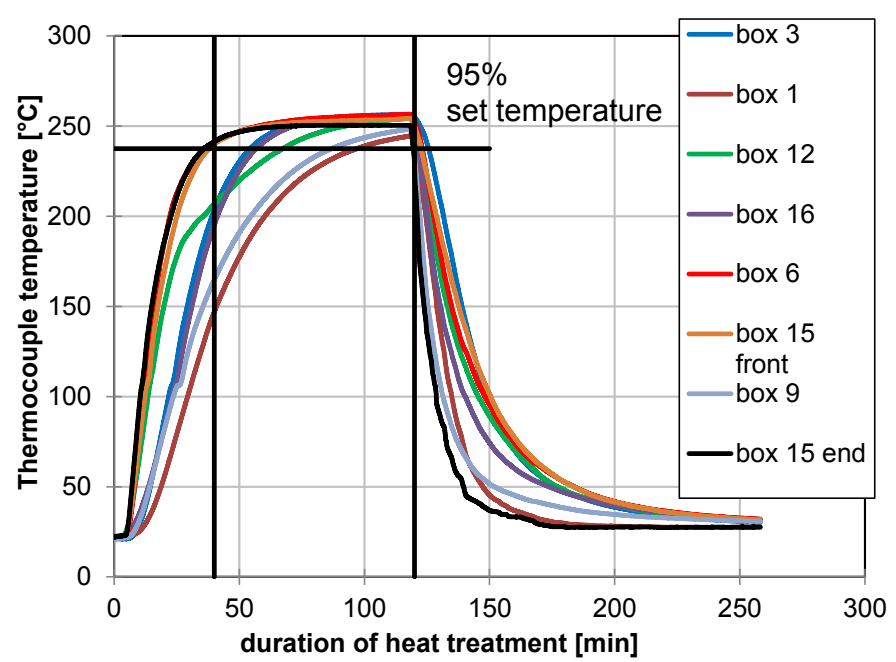

Fig. 4. Heating and cooling curves of springs in different boxes in a chamber furnace

A chamber furnace was loaded with 16 boxes filled with springs. Fig. 4 contains a diagram with heating and cooling curves measured on this springs with the help of thermocouples. The springs were arranged in different boxes on various places in the chamber furnace.

The heating curves of the different springs show large differences of up to 60 min until all springs have reached $95 \%$ of the set temperature. As to be seen in Fig. 4 the heat treatment influences not only the residual stresses but also the mechanical properties of the wire material.

So the question is: How do these different heat treatments influence the properties of a helical compression spring made from oil hardened and tempered wire? Or in other words: Did the heat treatment be successful in spite of differences in the heating curves? 


\section{Investigation of helical compression springs made from oil hardened and tempered wires}

The aim was to investigate the influence of different heating curves on the spring properties. That's why the heating curves measured in an industrial chamber furnace (cp. Fig. 4) were approximated by seven sampling points (Fig. 5) and were used for the heat treatment of sample springs in a reference furnace. Afterwards the spring properties were tested.

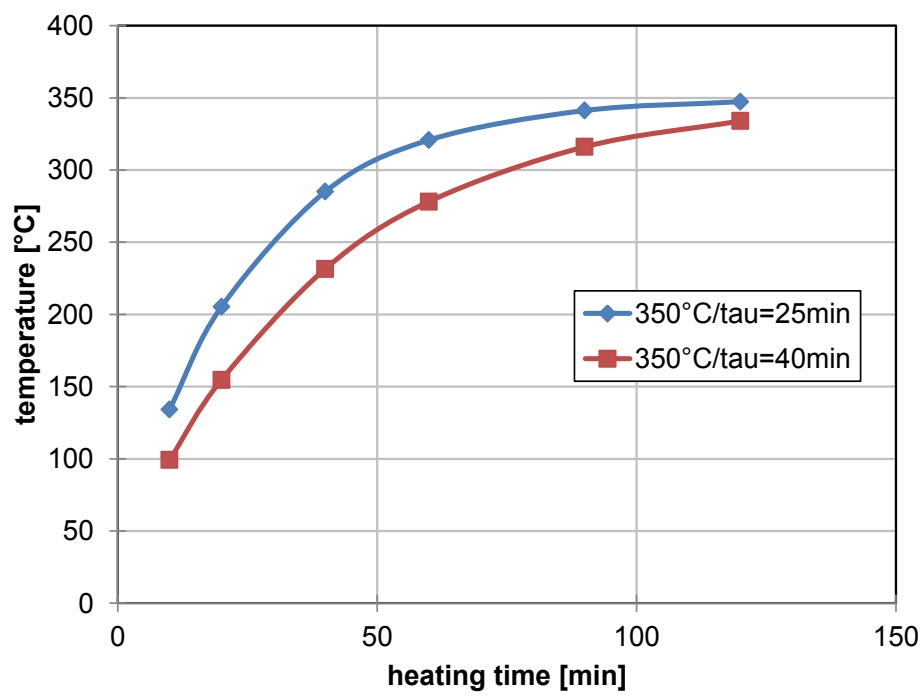

Fig. 5. Approximated heating curves of springs heat treated in a chamber furnace (cp. Fig. 4), variation of the time constant tau (at tau $63 \%$ of set temperature is reached)

The circulating air-chamber furnace of the research group (reference furnace) was controlled with these approximated heating curves. The set temperature was varied: $350^{\circ} \mathrm{C}$ and $420^{\circ} \mathrm{C}$. The heat treatment stopped after $120 \mathrm{~min}$. The properties of the heat treated springs above-mentioned were compared with springs heated $120 \mathrm{~min}$ on set temperature (these springs represent springs situated directly in the warm air flow) and with springs, tempered $30 \mathrm{~min}$ on set temperature (these springs represent prototype springs heat treated in a small chamber furnace).

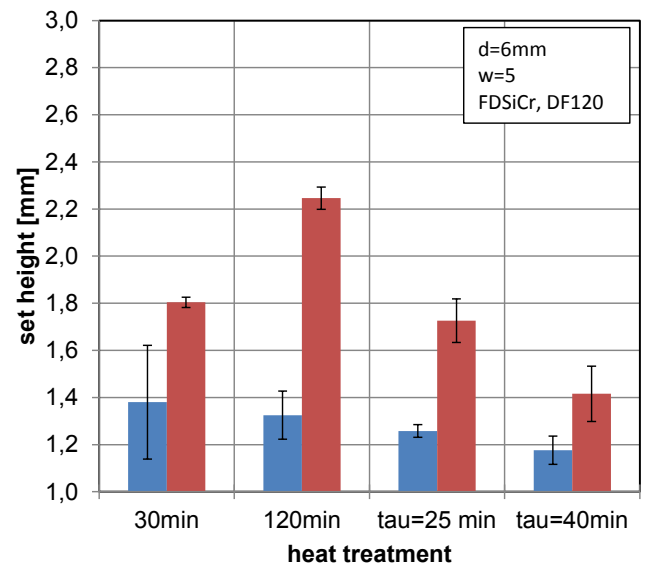

Fig. 6. Differences in the set heights of springs $\left(d=6 \mathrm{~mm}, \quad w=5\right.$ and $\left.n_{\mathrm{t}}=6.5\right)$ after different heat treatments at the same set temperature

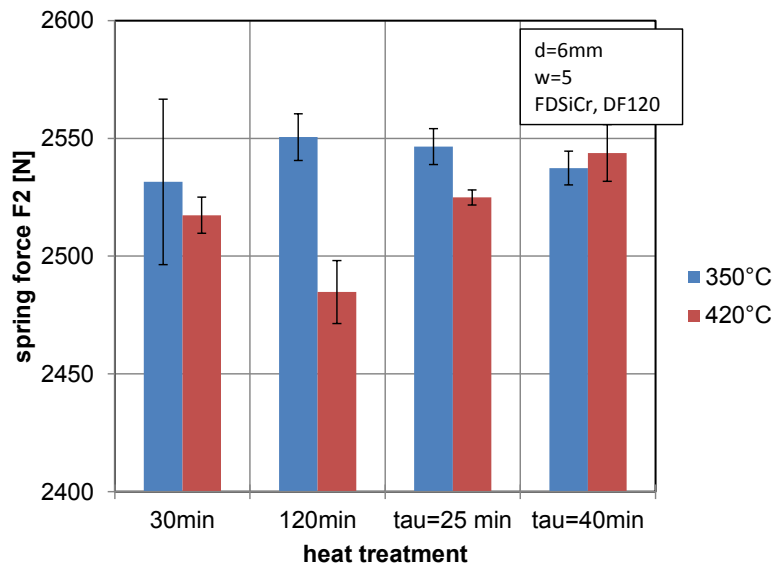

Fig. 7. Differences in the spring force F2 of springs $\left(d=6 \mathrm{~mm}, \quad w=5\right.$ and $\left.n_{\mathrm{t}}=6.5\right)$ after different heat treatments at the same set temperature

Fig. 6 shows the set heights after the presetting manufacturing step determined on heat treated springs with the described variation in the heat treatment procedure. The differences on the set heights on the springs are much greater after heat treatments with $420^{\circ} \mathrm{C}$ set temperature (approx. $0.8 \mathrm{~mm}$ ) as on springs after heat treatments with lower set temperatures (approx. $0.2 \mathrm{~mm}$ ). The variation of the spring force F2 is also much greater after a heat treatment with high set temperature 
$\left(420^{\circ} \mathrm{C}\right)$ (approx. $\left.60 \mathrm{~N}\right)$ then on with lower temperatures heat treated springs (approx. $20 \mathrm{~N}$ ). But nevertheless all springs met the requirements of quality grade 1 of DIN EN 15800 $\left(\mathrm{A}_{\mathrm{F}}(\mathrm{F} 2: \mathrm{Q} 1)=70 \mathrm{~N}\right)$. However, users of springs are increasingly demanding requirements of a half grade 1. In summary, it must be said, that for springs made of oil hardened wire (and heat treated at high temperatures) the heat treatment time significantly affects the spring parameters.

The success of a heat treatment can therefore be assessed only on the basis of required spring properties. According to this, the heat treatment must be carried out on the basis of the productspecific properties to be achieved. The heat treatment was successful, if all springs in the batch fulfill the spring parameters in the required tolerance.

\section{Summary}

For many applications, the heat treatment process of cold-formed springs is a very robust process. This means, that tolerances of heat treatment temperature and time (within the limits of the respective tolerance grade) mostly have only a slight effect on the properties of the spring. In the heat treatment of springs from oil hardened wire material with temperatures exceeding $400^{\circ} \mathrm{C}$ must be noted, that the strength properties of the springs are significantly affected and the heat treatment time greatly affects the spring properties. In addition, the reduction of the residual stresses is dependent on the heat treatment time (and temperature).

Gefördert durch:

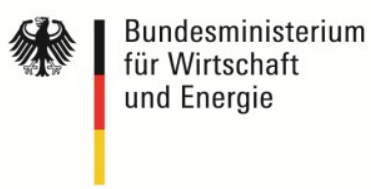

aufgrund eines Beschlusses des Deutschen Bundestages
Results presented here are from the research project IGF 17627BR. Funding was provided by the German Federal Ministry of Economics and Energy via the German Federation of Industrial Cooperative Research Associations „Otto von Guericke" (AiF) in the program to encourage the industrial Community research by an resolution of the German Bundestag and the Steel Forming Research Society (FSV).

\section{References}

[1] V. Geinitz, U. Kletzin, P. Beyer, Wärmebehandlung kalt geformter Federn, Final Report, IGF 17627BR (AiF), TU Ilmenau (2015)

[2] DIN EN 10270 Teil 1-3, Stahldraht für Federn (2012)

[3] M. Weiß, V. Geinitz, et al., Ermittlung von funktions- und fertigungsrelevanten Federdrahtkennwerten (E- und G-Modul), Final Report, IGF 14306 BR (AiF), TU Ilmenau (2007)

[4] V. Geinitz, M. Weiß, U. Kletzin, Funktions- und fertigungsrelevante Kennwerte für Federstahldraht und Federband, Final Report, IGF 16217 BR (AiF), TU Ilmenau (2011)

[5] R. Lux, P. Beyer, U. Kletzin, Langzeitstabilität der mechanischen Parameter patentiert gezogener Stahldrähte, Final Report, IGF 17043BR (AiF), TU Ilmenau (2013)

[6] DIN EN 15800, Zylindrische Schraubenfedern aus runden Drähten - Gütevorschriften für kaltgeformte Druckfedern (2008) 